\title{
Cat-Scratch Disease In Adult Hospitalized For Prolonged-Fever Associated With Multiple Lymphadenopathies and Weight Loss
}

\author{
Vincent Guiyedi* $^{* 1,2,3}$, Hanna Haddad ${ }^{4}$, Madeleine Okome-Nkoumou ${ }^{2,3}$, Fabien Gire ${ }^{1}$, Brice Ongali ${ }^{3}$, \\ Philippes Lore ${ }^{5}$ and Luis Gameiro ${ }^{1}$
}

\author{
${ }^{I}$ Service de Médecine B-Hepato-Gastro-Enterologie, Centre Hospitalier de Tulle, France \\ ${ }^{2}$ Département de Maladies Infectieuses et Tropicales, Faculté de Médecine de Libreville, Université des Sciences de la \\ Santé, Gabon \\ ${ }^{3}$ Service de Médecine Interne-Maladies Infectieuses et Tropicales, Centre Hospitalier Universitaire International Albert \\ Schweitzer de Lambaréné, Université des Sciences de la Santé, Libreville, Gabon \\ ${ }^{4}$ Service de Chirurgie Orthopédique, Centre Hospitalier de Tulle, France \\ ${ }^{5}$ Service de Médecine Interne-Rhumatologie-Neurologie, Centre Hospitalier de Tulle, France
}

\begin{abstract}
We report a 19-year-old patient with a Cat-scratch disease presenting three months continuous alteration of the general condition, including prolonged-fever, anorexia, asthenia, weight loss associated with adenitis and multiple thoracic-abdominal adenopathies, leukocytosis with neutrophil polynuclear predominance, and increased of C-reactive protein. The serologies of toxoplasmosis, infectious mononucleosis, human immunodeficiency virus, Brucellosis, Bartonellosis and the tuberculosis research by tuberculin reaction test and Ziehl acid-alcohol resistant bacilli direct examination were negatives. The cytomegalovirus and Epstein-Barr virus serologies were positives only for immunoglobulin-G. The Bartonella henselae diagnosis was made with the analysis of histopathological specimens. The clinical and biological symptoms regressed following eight weeks of azithromycin's treatment.

According to this observation, the cat-scratch disease should be considered in differential diagnosis of patients presenting prolonged-fever associated with multiple lymphadenopathies and weight loss. The azithromycin would be an alternative therapeutic issue for this pathology in case of confirmed efficacy by studies in a large patient population.
\end{abstract}

Keywords: Azithromycin, cat-scratch disease, weight loss, adenopathies, prolonged-fever.

\section{INTRODUCTION}

Cat-scratch disease is a bacterial infection caused by Bartonella henselae, a bacteria detected on the blood of healthy cats [1] which could be transmitted to humans after a skin injury caused by a scratch or bite responsible for regional lymph node enlargement [1]. Clinical manifestations include inflammatory lymphadenopathy and a papular lesion of the skin which develops at the site of the injury. Since the causative bacteria cannot be easily cultured from human lymph node samples, the diagnosis usually relies epidemiological, clinical, histological and serological criteria. We described Bartonella henselae infection in a 19 year old patient who presented prolonged fever, general state of alteration with weight loss, night sweats, asthenia, anorexia, biological inflammation and multiple superficial and thoracic-abdominal lymphadenopathies. This clinical

*Address correspondence to this author at the Service of Medecine B-Hepato-Gastro-Enterology, Tulle Hospital Center, France;

Tel: 00 (33) 05552980 45; Fax: 00 (33) 05552980 90;

E-mails: vincent.guiyedi@chui-asl.com; guidyvin@hotmail.com presentation is an exceptional diagnosis of adult Cat-scratch disease and could be mistaken for a neoplasm (lymphoma) or mycobacteriosis.

\section{CASE PRESENTATION}

Mr. A, born on December 7, 1993 (19 years old) was hospitalized from 10-12-2012 to 17-12-2012 in the Service of Medicine B-Hepato-Gastro-Enterology of Tulle Hospital Center, for adenopathy of internal-underside of left elbow with prolonged-fever. The medical antecedent revealed a complete vaccination, obesity and smoking. In the history of the disease, we noted a deterioration of general condition involving asthenia, anorexia and weight loss with a loss of $15 \mathrm{kgs}$ weight during the last three months (previous weight $105 \mathrm{~kg}$ ). The general condition deterioration syndrome worsened with the appearance of a significant swelling inside the left arm associated with alternating fever-apyrexia and night sweats. There was no antecedent of travel in the tropics, insect sting or bite. The patient was a butcher living with a kitten and was regularly scratched by it. He had no urinary or pulmonary functional signs. 
At the day of hospitalization the physical examination confimed the deterioration of general condition (asthenia, anorexia, weight loss), the temperature was $38.5^{\circ} \mathrm{C}$, weight $88 \mathrm{kgs}$, height $182 \mathrm{~cm}$, blood pressure $120 / 70 \mathrm{mmHg}$, there was no neurological, pulmonary or cardiovascular signs. The abdomen was soft, compressible, painless and had no hepatosplenomegaly. Clinical examination funded a left submaxillary and axillary infra centimeter adenopathies. The clinical examination which was otherwise unremarkable, revealed also an adenopathy with 5 to 6 centimeters of diameter at the internal face of the left elbow. This adenitis was firm, painful, moving and warm.

The laboratory tests performed on the day of admission (Day-0: D-0) highlighted: leukocytosis with neutrophil polynuclear predominance [White Blood Cells (WBC): 19.9 Giga/L, neutrophils Polunuclear: 14.5 Giga/L, C-reactive protein $(\mathrm{CrP}): 18 \mathrm{mg} / \mathrm{L}$ ] (Table 1). The remaining biological assessment, chest and left elbow radiographs were unremarkable, while the left elbow echography showed altered inflammatory of internal elbow soft tissue, consisting of a fluid collection, surrounded by a subcutaneous infiltration and lymph node swelling underlying. To complete medical and biological exploration, a thoracic-abdominal scanner highlighted several axillary, supraclavicular, mediastinal, hilar, iliac and inguinal centimeter lymph nodes.

In summary, this observation showed an impaired general condition syndrome in prolonged fever context with suppurative adenitis, weight loss and multiple lymphadenopathy in a young adult patient. The diagnostic hypotheses were rejected by the respective laboratory tests: toxoplasmosis, infectious monocucléose, HIV-1, HIV-2, Bartonellosis and Brucellosis serology were found to be negative. The intradermal reaction (IDR) to tuberculin and quantiferon assay was negative. The Cytomegalo virus (CMV) and Ebstein Barr virus (EBV) serologies were in favor of a previous infection. As the Bartonellosis serology was negative, the diagnosis of Cat-scratch disease was based on the pathological analysis of the biopsy specimen of the lymph node excisional which showed necrotizing granulomatous inflammation with central necrosis surrounded by epithelioid cells and Langhans' giant cells, strongly suggesting Bartonella henselae infection. The Ziehl coloration and cultures in search of Acido-Alcohol-Resistant Bacillus (AARB) were negative.

Taking into consideration the bacteriological results, a biempiric antibiotic therapy covering pyogenic and atypic germs was initiated (Amoxicillin-Clavulanic Acid: $1 \mathrm{~g}$ x 3 daily associated with Doxycycline: 2 x $100 \mathrm{mg}$ daily). Due to intolerance (nausea and vomiting) the Doxycicline was replaced by azithromycin ( $250 \mathrm{mg}$ daily). The clinical and biological outcomes were favorable although adenitis with 2 centimeters persisted for forty five days (D-45) after azithromycin treatment initialization (Table 1), thus justifying the continuation of this antibiotic treatment during eight weeks. The patient was also reviewed in consultation at day-75 (D-75) after the beginning of treatment. Clinical examination showed an overall decrease of the node diameter, absence of superficial lymph nodes, night sweats and asthenia, recovery of appetizing and stable weight of 86 $\mathrm{Kg}$.

\section{DISCUSSION}

Our observation examined the clinical, biological and imaging parameters in a patient hospitalized for a CatScratch disease in the service of Medicine B-Hépato-GastroEnterology of the Tulle Hospital Center (France). The Catscratch disease is seasonal disease in the United States of America, Japan and in France [2]. In this latter country, the analysis of lymph nodes biopsy specimens collected between 1999-2009 revealed that majority of cases suffering from this pathology occurred during September to April and peaked in December [2]. The period of our patient's hospitalization was in concordance with these previous observations and the differences in seasonality was explained by a homogeneous climate in France and the prevailing bacteria within the cat population [2].

Even if little is known about Cat-scratch disease pathogenesis, the role of immunological mechanisms was previously related and implication of both humoral and/or cellular immune responses in the disease physiopathology remained unclear in human and murine models [3-6]. Indeed, the severity of clinical presentation correlates with the status of the hosts' immune system, as the role of the host immune response to Bartonella henselae in the disease manifestation has been illustrated in patients with Acquired ImmunoDeficient Syndrome (AIDS) in which Bartonella henselae progresses to systemic infection more often, including bacillary angiomatosis or bacillary peliosis hepatis, while in immunocompetent patients, a self-limited regional lymphadenopathies involving resulting from a strong cellular immune response to bacterium are usually observed $[6,7]$. However, the dissemination of Bartonella henselae is

Table 1. Clinical and Biological Parameters Evolution between Day-0 (D-0) Corresponding to the Day of Patient Hospitalization and Day-75. D: Day, Temp: Body Temperature, ADP: Adenopathies, Asth: Astnenie, Anor: Anorexia, Pla: Platelets, WBC: Weight Blood Cells, Neut: Neutrophils, Lym: Lymphocytes, Hb: Haemoglobin rate, Creat: Creatinine, CrP: CReactive Protein

\begin{tabular}{|c|c|c|c|c|c|c|c|c|c|c|c|c|}
\hline & $\begin{array}{c}\text { Weight } \\
\text { (Kgs) }\end{array}$ & $\begin{array}{c}\text { Temp } \\
\left({ }^{\circ} \mathrm{C}\right)\end{array}$ & $\begin{array}{l}\text { ADP } \\
(\mathrm{Cm})\end{array}$ & Asth. & Anor. & Pla. $\left(\mathrm{mm}^{3}\right)$ & $\begin{array}{l}\text { WBC } \\
\left(\mathbf{m m}^{3}\right)\end{array}$ & $\begin{array}{l}\text { Neut } \\
\left(\mathbf{m m}^{3}\right)\end{array}$ & Lym. $\left(\mathbf{m m}^{3}\right)$ & $\begin{array}{c}\mathbf{H b} \\
(\mathrm{g} / \mathrm{dL})\end{array}$ & $\begin{array}{c}\text { Creat } \\
.(\mathrm{mg} / \mathrm{L})\end{array}$ & $\begin{array}{c}\mathrm{CrP} \\
(\mathrm{mg} / \mathrm{L})\end{array}$ \\
\hline D-0 & 88 & 38.5 & 6 & Yes & Yes & 261000 & 19900 & 14500 & 3600 & 14.9 & 8 & 18 \\
\hline D-7 & 87 & 37 & 5 & Yes & Yes & 203000 & 10800 & 6500 & 3300 & 14.1 & 7 & 10 \\
\hline D-45 & 86 & 37.2 & 2 & no & no & 259000 & 10200 & 4900 & 4200 & 15.6 & 8 & 3 \\
\hline
\end{tabular}


observed in other immunodeficient states, such as chronic lymphocytic leukaemia and T cell lymphoma $[8,9]$. In fact, our observation is in concordance with an immune response in immunocompetent adult as neither a deficit in leukocytes and lymphocytes number nor a negative HIV serology were observed.

The patient presented altered general syndrome, prolonged-fever, weight loss and multiple adenopathies. The tuberculosis and malignant pathology are usually associated with differential diagnosis of this type of clinical presentation. It was remarkable to shown that no tuberculosis or neoplasm was identified and the diagnosis was confirmed by specimen's histopathological examination, while Bartonella henselae serology, direct or culture examination and histopathological Mycobacteriosis research were found to be negative. According to previous observations, the diagnosis of Cat-scratch disease does not eliminate the risk of mycobacteriosis or neoplasm [10]. As some patients might have a concurrent mycobacteriosis chronic pathology or malignant disease, therefore histological analysis of lymph node biopsy specimens should be routinely performed in patients with suspected Cat-scratch disease [10]. This is amplified by observating Bartonella henselae infection mimicking a splenic lymphoma, Richter's syndrome in patient with chronic lymphocytic leukemia or multiple sclerosis $[8,11,12]$. Similarly, lymph node enlargement is a common medical problem observed both in infectious diseases caused by bacterial, viral, protozoal agents and in malignancies or lymphoproliferative diseases [13]. In medical practise the cause of lymphadenopathy remained undiagnosed in a large number of patients. It has been recently reported that Bartonella henselae could also be considered a cause of lymphadenopathies in febrile altered general condition context [13-15]. This disease is usually revealed by lymphadenopathies related to the inoculation site in patient receiving cat scratch or bites. Even if, Cat-Scratch serology tests were negative, histopathological examination of lymph node biopsy specimens would have shown necrotizing granulomatous inflammation with central necrosis surrounded by epithelioid cells and Langhans' giant cells, strongly suggesting Bartonella henselae infection. According to the present case report, combination of both serologic tests with histopathologic examination with or without Polymerase chain reaction test (PCR) in the tissue specimen must to be considered for the Cat-scratch disease diagnosis in adult patients presenting prolonged-fever, weight loss and multiple adenopathies, as the presence of these symptoms has been previously described in this pathology $[10,11,16-19]$. The bone involvement of Bartonella henselae is rare and revealed the possibility of a systemic form of the disease, which could mimic a splenic lymphoma $[11,18,20,21]$.

The treatment of Cat Scratch disease depends on the disease presentation. In case of self-limited lymphadenopathy antibiotics are not required and there is a favourable evolution of the symptoms in two to eight weeks. In the present case report, the patient was presented with alterations in the general condition with asthenia, anorexia and weight loss during three months and justifies antibiotic treatment. A specific treatment of Bartonella hanselae infection is not available and antibiotics have a less bactericidal effects on these bacteria [22]. The treatment failures and relapses are frequent, especially following brief antibiotic courses and justifying prolonged treatment [23]. As the use of Azithromycin led to a more rapid resolution of lymphadenopathy in previous observation, our patient was treated with this antibiotic and the treatment was prolonged on eight weeks to obtain a total resolution of clinical symptoms and adenopathies [24]. There is a small number of studies investigating the efficacy of antibiotics in Cat-scratch disease. According to previous and current observation azithromycin would be an appropriate treatment alternative in adult patients, but randomized trials with significant number of patients are necessary in all countries to standardized the therapeutic recommendations [25].

\section{CONCLUSION}

In respect to previous observations and our case report, Cat-scratch disease should be considered in the differential diagnosis of adult patients, presenting altered general condition with prolonged-fever associated to multiple lymphadenopathies and weight loss. The azithromycin would be a therapeutic alternative for Cat-scratch disease treatment if its efficacy is confirmed by studies in a large population of patients developing this pathology.

\section{CONFLICT OF INTEREST}

The authors confirm that this article content has no conflicts of interest.

\section{ACKNOWLEDGMENTS}

None declared.

\section{REFERENCES}

[1] Klotz SA, Ianas V, Elliott SP. Cat-scratch Disease. Am Fam Physician 2011; 83:152-5.

[2] Sanguinetti-Morelli D, Angelakis E, Richet H, et al. Seasonality of cat-scratch disease, France, 1999-2009. Emerg Infect Dis 2011; 17(4): 705-7.

[3] Karem KL, Dubois KA, McGill SL, Regnery RL. Characterization of Bartonella henselae-specific immunity in $\mathrm{BALB} / \mathrm{c}$ mice. Immunology 1999; 97(2): 352-8.

[4] Vermi W, Facchetti F, Riboldi E, et al. Role of dendritic cellderived CXCL13 in the pathogenesis of Bartonella henselae B-rich granuloma. Blood 2006; 107(2): 454-62.

[5] Vigil EA, Ortega R, Jain A, et al. Identification of the feline humoral immune response to Bartonella henselae infection by protein microarray. PLoS One 2010; 5(7): e11447.

[6] Resto-Ruiz S, Burgess A, Anderson BE. The role of the host immune response in pathogenesis of Bartonella henselae. DNA Cell Biol 2003; 22(6): 431-40.

[7] Resto-Ruiz S, Burgess A, Anderson BE. The role of the host immune response in pathogenesis of Bartonella henselae. DNA Cell Biol 2003; 22(6): 431-40.

[8] Razaq M, Godkar D, Mankan N, Sridhar S, Hussain S, Ohri A. Cat scratch disease mimicking Richter's Syndrome in a patient with chronic lymphocytic leukemia. Leuk Lymphoma 2005; 46(3): 4435 .

[9] Jeong W, Seiter K, Strauchen J, et al. PET scan-positive cat scratch disease in a patient with $\mathrm{T}$ cell lymphoblastic lymphoma. Leuk Res 2005; 29(5): 591-4.

[10] Rolain JM, Lepidi H, Zanaret M, et al. Lymph node biopsy specimens and diagnosis of cat-scratch disease. Emerg Infect Dis 2006; 12(9): 1338-44. 
[11] Ghez D, Bernard L, Bayou E, Bani-Sadr F, Vallée C, Perronne C. Bartonella henselae infection mimicking a splenic lymphoma. Scand J Infect Dis 2001; 33(12): 935-6.

[12] Gaubitz M, Herrmann M, Shahin M, Schotte H, Willeke P, Domschke W. Cat scratch disease (bartonellosis) mimicking an SLE flare. Lupus 2001; 10(12): 883-5.

[13] Ridder GJ, Boedeker CC, Technau-Ihling K, Grunow R, Sander A. Role of cat-scratch disease in lymphadenopathy in the head and neck. Clin Infect Dis 2002; 35(6): 643-9.

[14] Carithers HA. Cat-scratch disease. An overview based on a study of 1,200 patients. Am J Dis Child 1985; 139(11): 1124-33.

[15] Margileth AM. Antibiotic therapy for cat-scratch disease: clinical study of therapeutic outcome in 268 patients and a review of the literature. Pediatr Infect Dis J 1992; 11(6): 474-8.

[16] Eglantin F, Hamdad F, El Samad Y, et al. The diagnosis of catscratch-disease-associated adenitis: diagnostic value of serology and polymerase chain reaction. Pathol Biol 2008; 56(7-8): 461-6.

[17] Hansmann Y, DeMartino S, Piémont Y, et al. Diagnosis of cat scratch disease with detection of Bartonella henselae by PCR: a study of patients with lymph node enlargement. J Clin Microbiol 2005; 43(8): 3800-6.

[18] Ismaili-Alaoui N, Vuong V, Marcu-Marin M, Sergent-Alaoui A, Chevallier B, de Labriolle-Vaylet C. Cat-scratch disease and bone scintigraphy. Clin Nucl Med 2012; 37(8): 772-4.
[19] Dekkers MJ, Dees A, Weidema WF, Bartelsman M, Veeken $\mathrm{H}$, Hart W. Clinical thinking and decision making in practice. A man with abdominal pain, weight loss and fever. Ned Tijdschr Geneeskd 2009; 153(5): 174-80.

[20] Bhatti Z, Berenson CS. Adult systemic cat scratch disease associated with therapy for hepatitis C. BMC Infect Dis 2007; 23: 7-8.

[21] Liao HM, Huang FY, Chi H, Wang NL, Chen BF. Systemic cat scratch disease. J Formos Med Assoc 2006; 105(8): 674-9.

[22] Bass JW, Freitas BC, Freitas AD, et al. Prospective randomized double blind placebo-controlled evaluation of azithromycin for treatment of cat-scratch disease. Pediatr Infect Dis J 1998; 17(6): 447-52.

[23] Musso D, Drancourt M, Raoult D. Lack of bactericidal effect of antibiotics except aminoglycosides on Bartonella (Rochalimaea) henselae. J Antimicrob Chemother 1995 Jul; 36(1): 101-8.

[24] Karris MY, Litwin CM, Dong HS, Vinetz J. Bartonella henselae infection of prosthetic aortic valve associated with colitis. Vector Borne Zoonotic Dis 2011; 11(11): 1503-5.

[25] Klotz SA, Ianas V, Elliott SP. Cat-scratch Disease. Am Fam Physician 2011; 83(2): 152-5.

(C) Guiyedi et al.; Licensee Bentham Open.

This is an open access article licensed under the terms of the Creative Commons Attribution Non-Commercial License (http://creativecommons.org/licenses/by-nc/3.0/) which permits unrestricted, non-commercial use, distribution and reproduction in any medium, provided the work is properly cited. 